\title{
PENYULUHAN METODE AUDIO VISUAL DAN DEMONSTRASI TERHADAP PENGETAHUAN MENYIKAT GIGI PADA ANAK SEKOLAH DASAR
}

\author{
Prasko $^{\bowtie 1}$, Bambang Sutomo $^{2}$, Bedjo Santoso $^{3}$
}

\begin{abstract}
ABSTRAK
Upaya pemeliharaan kesehatan gigi dan mulut serta pembinaan kesehatan gigi terutama pada anak kelompok sekolah perlu mendapat perhatian khusus sebab pada usia ini anak sedang menjalani proses tumbuh kembang. Keadaan gigi sebelumnya akan berpengaruh terhadap perkembangan kesehatan gigi pada usia dewasa nanti. Melalui program penyuluhan diharapkan dapat meningkatkan pengetahuan dan menumbuhkan kesadaran akan pentingnya menjaga kesehatan gigi dan mulut dan dapat berpartisipasi secara aktif dalam meningkatkan upaya pelihara diri. Tujuan penelitian ini adalah mengetahui efektifitas penyuluhan metode audio visual dan demonstrasi terhadap pengetahuan menyikat gigi.

Jenis penelitian ini menggunakan metode deskriptif kuantitatif yaitu suatu metode penelitian yang dilakukan dengan tujuan utama untuk membuat gambaran atau deskripsi tentang suatu keadaan secara objektif yang ada hubungannya dengan masalah yang diteliti. Instrumen yang dipergunakan adalah dengan kuesioner.

Dari hasil penelitian yang dilakukan peneliti dilapangan terhadap siswa kelas $V$ dan VI SDN Pedalangan 02 Semarang dapat diketahui bahwa setelah dilakukan penyuluhan dengan demonstrasi didapatkan hasil pengetahuan siswa kelas $V$ masuk kategori baik dengan nilai 7 dan setelah dilakukan penyuluhan dengan audio visual didapatkan hasil pengetahuan siswa kelas VI masuk kategori baik dengan nilai 6,95. Maka dapat disimpulkan bahwa penyuluhan demonstrasi dan penyuluhan dengan audio visual efektif untuk digunakan dalam meningkatkan pengetahuan menyikat gigi pada anak sekolah dasar.
\end{abstract}

Kata kunci : Penyuluhan Metode Demonstrasi dan audio Visual, Pengetahuan Menyikat Gigi

\begin{abstract}
The maintenance of oral health as well as health coaching teeth, especially in children of school groups need special attention because at this age children are undergoing the process of growth and development. Previous dental state will affect the development of dental health in adulthood. Through training programs is expected to increase knowledge and raise awareness of the importance of maintaining oral health and able to participate actively in increasing efforts to maintain self. The purpose of this research was to determine the effectiveness of extension methods and audio visual demonstration of the knowledge brushing teeth.

This research uses descriptive quantitative method is a method of research conducted with the main objective to create a picture or a description of a situation in an objective that has to do with the problems examined. The instrument used was the questionnaire.

From the results of the study conducted by researchers in the field to the students of class V and VI Elementary School Pedalangan 02 Semarang is known that after counseling with the demonstration of the results obtained knowledge of students of class $V$ in both categories with a score of 7 and after counseling with audio visual results obtained knowledge graders VI enter both categories with a value 6.95. It can be concluded that the extension demonstration and extension with audio visual effective for use in improving the knowledge toothbrushing on elementary school children.
\end{abstract}

Key words : Counseling method of demonstration and audio visual, knowledge of brushing teeth

\footnotetext{
,.) Dosen Jurusan Keperawatan Gigi Poltekkes Kemenkes Semarang

: praskoabdullah@yahoo.co.id
} 


\section{PENDAHULUAN}

Pembangunan kesehatan bertujuan untuk meningkatkan kesadaran, kemauan, dan kemampuan hidup sehat bagi setiap orang agar terwujud derajat kesehatan masyarakat yang optimal. Untuk mewujudkan derajat kesehatan yang optimal bagi masyarakat, diselenggarakan upaya kesehatan dengan pendekatan pemeliharaan, peningkatan kesehatan (promotif), pencegahan penyakit (preventif), penyembuhan penyakit (kuratif), dan pemulihan kesehatan (rehabilitatif) yang dilaksanakan secara menyeluruh, terpadu dan berkesinambungan (Depkes RI, 2000).

Upaya pemeliharaan kesehatan gigi dan mulut serta pembinaan kesehatan gigi terutama pada anak kelompok sekolah perlu mendapat perhatian khusus sebab pada usia ini anak sedang menjalani proses tumbuh kembang.Keadaan gigi sebelumnya akan berpengaruh terhadap perkembangan kesehatan gigi pada usia dewasa nanti.

Program pembangunan nasional bertujuan untuk mengubah perilaku masyarakat kearah perilaku sehat. Perencanaan program penyuluhan merupakan serangkaian kegiatan yang disusun secara sistematis dan ditetapkan bersama untuk mengubah perilaku masyarakat kearah perilaku sehat (Artini, dkk, 2002). Penyuluhan kesehatan gigi adalah usaha terencana dan terarah untuk menciptakan suasana agar seseorang atau kelompok masyarakat mau mengubah perilaku lama yang kurang menguntungkan untuk kesehatan gigi, menjadi lebih menguntungkan untuk kesehatan gigi (Budiharto, 2009).

Melalui program penyuluhan diharapkan dapat meningkatkan pengetahuan dan kesadaran masyarakat akan pentingnya menjaga kesehatan gigi dan mulut dan dapat berpartisipasi secara aktif dalam meningkatkan upaya pelihara diri. Selain itu dengan penyuluhan, seseorang bisa mengupayakan diri dalam usaha pencegahan penyakit gigi dan mulut (Setyaningsih, 2007).

Penyampaian materi penyuluhan kepada sasaran selain harus sesuai dengan metode yang akan digunakan juga dipengaruhi oleh ada tidaknya alat bantu atau sarana media pendukung untuk penyampaian. Demonstrasi dan metode yang lainnya merupakan salah satu cara menyajikan informasi dengan cara mempertunjukkan secara langsung objeknya atau menunjukkan suatu proses atau prosedur. Penyajian ini disertai penggunaan alat peraga dan media sebagai alat bantu penyampaian materi. Penyuluhan yang efektif diberikan kepada kelompok individu yang tidak terlalu besar jumlahnya (Artini, $\mathrm{dkk}, 2002)$.

Media sebagai alat bantu dalam proses belajar mengajar adalah suatu kenyataan yang tidak dapat dipungkiri (Djamaroh, 2006). Alat bantu atau media sangat penting ketika dipergunakan untuk penyuluhan, karena alat bantu digunakan oleh pendidik dalam menyampaikan bahan pendidikan atau pengajaran (Astoeti, 2006).

Tujuan penelitian ini adalah mengetahui efektifitas penyuluhan metode audio visual dan demonstrasi terhadap pengetahuan menyikat gigi.

\section{METODE PENELITIAN}

Jenis penelitian ini menggunakan metode deskriptif kuantitatif yaitu suatu metode penelitian yang dilakukan dengan tujuan utama untuk membuat gambaran atau deskripsi tentang suatu keadaan secara objektif yang ada hubungannya dengan masalah yang diteliti yaitu membandingkan efektifitas penyuluhan metode demonstrasi dan metode audio visual terhadap pengetahuan menyikat gigi pada siswa kelas V dan VI SDN Pedalangan 02 Semarang. Pendekatan penelitian yang digunakan dalam penelitian ini menggunakan cross sectional yaitu dengan pendekatan, observasi, atau pengumpulan data sekaligus pada suatu saat. 
Artinya, tiap subjek penelitian hanya diobservasi sekali saja dan pengukuran dilakukan terhadap status variable subjek pada saat pemeriksaan (Notoatmojo, 2005).

Pengumpulan data dalam penelitian ini menggunakan teknik kuesioner yang dilakukan peneliti kepada siswa kelas V dan VI SDN 02 Pedalangan.

Analisa data berisi cara-cara menganalisis, bagaimana memanfaatkan data yang telah terkumpul untuk digunakan dalam pemecahan masalah penelitiaan, data yang terkumpul harus dipisah-pisahkan menurut kategori masing-masing dan kemudian ditafsirkan dalam usaha mencari jawaban masalah. Analisa data yang digunakan untuk membahas data yang diperoleh dari penelitian setelah data terkumpul, selanjutnya digunakan untuk penarikan kesimpulan. Metode analisa data yang digunakan dalam deskriptif kuantitatif. Analisa deskriptif kuantitatif yang mendeskripsikan hasil penelitian melalui prosentase tabulasi, kemudian memaparkan rata-rata selisih dari kedua metode penyuluhan.

\section{HASIL DAN PEMBAHASAN}

Tabel 1. Kedaan pengetahuan sebelum dan sesudah diberi penyuluhan dengan demontrasi

\begin{tabular}{|c|c|c|c|c|}
\hline \multirow{2}{*}{$\begin{array}{c}\text { TINGKAT } \\
\text { PENGETA- } \\
\text { HUAN }\end{array}$} & \multicolumn{2}{|c|}{ SEBELUM } & \multicolumn{2}{|c|}{ SESUDAH } \\
\hline & $\mathrm{f}$ & $\%$ & $\mathrm{f}$ & $\%$ \\
\hline Kurang & 8 & 40.0 & 0 & 0.0 \\
\hline Sedang & 12 & 60.0 & 15 & 75.0 \\
\hline Baik & 0 & 0.0 & 5 & 25.0 \\
\hline Total & 20 & 100.0 & 20 & 100.0 \\
\hline
\end{tabular}

Tabel 1 di atas dapat dilihat bahwa sebelum dilakukan penyuluhan dengan metode demonstrasi keadaan responden dengan proporsi paling besar adalah pengetahuan dengan kategori sedang 12 orang $(60 \%)$, dan yang paling kecil adalah kategori baik $(0 \%)$. Untuk keadaan tingkat pengetahuan sesudah diberi penyuluhan dengan demontrasi menunjukkan bahwa proporsi paling besar adalah kategori sedang 15 orang $(75 \%)$, dan yang paling kecil adalah kategori kurang ( $0 \%$ )

Secara deskriptip hasil penelitian menunjukkan adanya perubahan tingkat pengetahuan pada siswa, dimana untuk sebelum perlakuan masih ditemukan siswa dengan tingkat pengetahuan kurang serta tidak ditemukan tingkat pengetahuan baik. Sesudah perlakuan demontrasi terjadi perubahan sebaliknya kearah positip yaitu tidak ditemukan lagi kategori kurang, tetapi terjadi perubahan ke kategori baik dari yang sebelum perlakuan tidak ada.

Adanya perubahan ini didukung dengan hasil uji statistik dengan Paired $T$ Test didapatkan p.value $=0,000$. keadaan ini menunjukkan bahwa $\mathrm{Ho}$ ditolak dan $\mathrm{Ha}$ diterima, ada perbedaan yang bermakna perubahan tingkat pengetahuan sebelum dan sesudah pada kelompok responden yang diberi perlakuan ceramah dengan demonstrasi.

Tabel 2. Kedaan pengetahuan sebelum dan sesudah diberi penyuluhan dengan audio visual.

\begin{tabular}{|l|r|r|r|r|}
\hline \multirow{2}{*}{$\begin{array}{c}\text { TINGKAT } \\
\text { PENGETA- }\end{array}$} & \multicolumn{2}{|c|}{ SEBELUN } & \multicolumn{2}{c|}{ SESUDAH } \\
\cline { 2 - 5 } Kurang & 5 & 25.0 & 0 & 0.0 \\
\hline Sedang & 15 & 75.0 & 12 & 60.0 \\
\hline Baik & 0 & 0.0 & 8 & 40.0 \\
\hline Total & 20 & 100.0 & 20 & 100.0 \\
\hline
\end{tabular}

Tabel 2 di atas dapat dilihat bahwa sebelum dilakukan penyuluhan dengan audio visual keadaan responden dengan proporsi paling besar adalah pengetahuan dengan kategori sedang 15 orang (75\%), dan yang paling kecil adalah kategori baik (0\%). Untuk keadaan tingkat pengetahuan sesudah diberi penyuluhan dengan audio visual menunjukkan bahwa proporsi paling besar adalah kategori sedang 12 orang $(60 \%)$, dan paling kecil adalah kategori kurang $(0 \%)$. 
Secara deskriptip hasil penelitian menunjukkan adanya perubahan tingkat pengetahuan pada siswa yang diberikan penyuluhan dengan audio visual dari kategori kurang ke kategori sedang, serta adanya perubahan ke kategori baik, dimana pada sebelum perlakuan kategori baik tidak ada.

Adanya perubahan ini didukung dengan hasil uji statistik dengan Paired $T$ Test didapatkan p.value $=0,000$. keadaan ini menunjukan bahwa Ho ditolak dan $\mathrm{Ha}$ diterima, ada perbedaan yang bermakna perubahan tingkat pengetahuan sebelum dan sesudah pada kelompok responden yang diberi perlakuan penyuluhan dengan audio visual.

Secara keseluruhan dari kedua perlakuan untuk kelompok perlakuan penyuluhan dengan demonstrasi dan ceramah dengan sesudah demonstrasi sama-sama bisa meberikan perubahan pengetahuan menuju kearah sedang dan baik.

Hasil penelitian setelah dilakukan penyuluhan menggunakan metode audio visual menunjukkan bahwa skor pengetahuan anak sebagian besar (60\%) masuk pada kriteria sedang. Hal ini berarti metode audio visual bisa berguna untuk meningkatkan pengetahuan anak.

Pengetahuan siswa yang meningkat karena metode audio visual ini sangat menarik dan media audio visual menyajikan bahan pelajaran dengan menggunakan alatalat media pengajaran yang dapat memperdengarkan, atau memperagakan bahan-bahan tersebut sehingga murid-murid dapat menyaksikan secara langsung, mengamat-amati secara cermat.

Adanya hasil yang menunjukkan bahwa sebagian besar dalam kriteria sedang hal dimungkinkan adanya kelemahan pada metode penyuluhan audio visual. Durasi pemutaran video ini dilakukan tanpa berhenti sehingga daya tangkap sasaran sangat berpengaruh terhadap pemahaman dan pengetahuan siswa.
Hasil penelitian setelah dilakukan penyuluhan menggunakan metode demonstrasi menunjukkan bahwa skor pengetahuan anak sebagian besar atau 75 persen masuk pada kriteria yang sedang. Hal ini berarti metode demonstrasi bisa berguna untuk meningkatkan pengetahuan anak.

Penyuluhan menggunakan demonstrasi memiliki kelebihan proses penerimaan sasaran terhadap materi penyuluhan akan lebih berkesan secara mendalam sehingga membentuk pengertian dengan baik dan sempurna, terlebih bila peserta ikut serta secara aktif. Orang biasanya akan lebih percaya pada sesuatu yang dilihat atau dikerjakan daripada yang didengar atau dibaca dan akan lebih percaya kalau dapat mengerjakan. Peragaan dapat diulang dan dicoba oleh peserta dengan suasana santai serta benda yang digunakan benar-benar nyata.

Adanya hasil yang menunjukkan bahwa sebagian besar masuk dalam kriteria pengetahuan kriteria sedang hal dimungkinkan adanya kelemahan pada metode penyuluhan. Apabila alat / benda yang diperagakan termasuk alat berat atau agak rumit, atau jumlahnya terbatas, hanya beberapa orang yang mempunyai kesempatan untuk mempraktekannya.

Hasil nanalisis inferensial menunjukkan bahwa metode demontrasi dibandingkan dengan audio visual didapatkan p.value $=0,397$, tidak ada perbedaan perubahan tingkat pengetahuan yang bermakna anatar metode demontrasi dan media audio viual. namun secra deskriptip menunjukkan bahwa pada penyuluhan dengan menggunakan metode demontrasi lebih efektif dibandingkan dengan metode audio visual, hal ini dapat dilihat dari nila rata-rata demontrasi 2,1 lebih besar dibanding dari nilai rata-rata perubahan pada media audio visual nilai tertinggi 1,8 . selain itu nilai selisih tertinggi pada demontrasi sebesar 4 lebih besar dibandingkan dengan nilai selisih tertinggi pada audio visual yaitu 3 . 
Adanya kondisi ini sesuai dengan teori Edgar dale yang mengatakan bahwa semakin konkrit media maka tingkat penerimaan sasaran menjadi lebih baik, sebaliknya semakin abstrak sebuah media maka tingkat penerimaan menjadi kurang. Dalam hal ini demonstrasi lebih memberikan pengalaman konkrit kepada sasaran, karena dengan demonstrasi sasaran diberikan pengalaman langsung untuk melihat langsung lebih dekat.

\section{KESIMPULAN}

1. Penyuluhan menggunakan media audio visual efektif meningkatkan pengetahuan sasaran siswa SD hal ini terlihat dari mayoritas sasaran memiliki pengetahuan menyikat gigi yang baik.

2. Penyuluhan menggunakan metode demonstrasi juga efektif meningkatkan pengetahuan sasaran siswa SD hal ini terlihat dari mayoritas sasaran juga memiliki pengetahuan menyikat gigi yang baik.

3. Secara deskriptip metode penyuluhan menggunakan demontrasi lebih efektif dibandingkat audio visual.

\section{SARAN}

1. Metode audio visual dapat diberikan secara berkala oleh guru untuk meningkatkan pengetahuan siswa terkait dengan pengetahuan kesehatan gigi dan mulut.

2. Pada pelaksanaan penyuluhan demonstrasi sebaiknya dibuat kelompok kecil sehingga lebih efektif dalam penyampaian demonstrasinya.

\section{DAFTAR PUSTAKA}

Artini, Eliza, Indriyani, 2002. Pendidikan Kesehatan Gigi. Kedokteran EGC : Jakarta
Astoeti, T. E, 2006. Total Quality Management Dalam Pendidikan Kesehatan Gigi Sekolah. Raja Grafindo Persada : Jakarta

Budiharto, 2009. Pengantar Ilmu Perilaku Kesehatan Dan Pendidikan Kesehatan Gigi. Kedokteran EGC : Jakarta

Depkes RI, 2000, Pedoman Pelayanan Kesehatan Gigi dan Mulut, Depkes RI: Jakarta

Djamaroh, Bahri,S., Zain,A., 2006. Strategi Belajar Mengajar. Rineka Cipta : Jakarta

Herijulianti, E, Indriani, T.S, Artini S, 2002.Pendidikan Kesehatan Gigi.Kedokteran EGC : Jakarta

Notoatmodjo,S, 2005. Metodologi Penelitian Kesehatan. Rineka Cipta : Jakarta

Setyaningsih, D, 2007. Menjaga Kesehatan Gigi Dan Mulut. CV.Sinar Cemerlang Abadi : Jakarta

Undang-Undang RI, Nomor 36 Tahun 2009 Tentang Kesehatan 